\title{
Short Communication: Identification of the Aroma Compounds Responsible for the Floral/Rose Flavor in Water-Soluble Fractions of Manchego Cheese
}

\author{
P. López Soto-Yarritu, ${ }^{*}$ L. Amigo, $\dagger$ G. Taborda, $\dagger^{1}$ I. Martínez-Castro, ${ }^{*}$ and J. A. Gómez-Ruiz $\dagger^{2,3}$ \\ *Instituto de Química Orgánica General, Consejo Superior de Investigaciones Cientificas (CSIC), and \\ †Instituto de Fermentaciones Industriales, CSIC, Juan de la Cierva 3, 28006 Madrid, Spain
}

\begin{abstract}
Water-soluble fractions from Protected Denomination of Origin Manchego cheese, with molecular weight $<1,000 \mathrm{Da}$, were fractionated using gel permeation chromatography and studied using both instrumental and sensorial analysis. In 2 of the fractions, panelists detected a floral, rose-like flavor. Analysis of these fractions by gas chromatography-mass spectrometry after simultaneous distillation extraction with dichloromethane identified 2-phenylethanol and phenylacetaldehyde as the compounds responsible for this flavor.

Key words: floral/rose flavor, Manchego cheese, 2-phenylethanol, phenylacetaldehyde

Several hundreds of volatile components have been identified in cheese. Cheese flavor is the result of a balance among various volatile substances that individually do not reflect the overall flavor. However, some of these substances possess very low detection thresholds and, therefore, play an important role in cheese flavor. Even though part of the volatile compounds are dissolved in fat or conjugated with insoluble substances, it seems that those present in the water-soluble fraction (WSF) could play an important role in cheese flavor (Salles et al., 1995; Engels et al., 1997). In a previous study in our laboratory (unpublished data), WSF with molecular weight $<1,000$ Da were fractionated using gel permeation chromatography. The different fractions were studied to establish and compare the relationships between the peculiar organoleptic characteristics of raw and pasteurized Manchego cheeses and the flavor compounds. A very clear floral aroma was detected in 2 of these fractions by a panel of trained members; never-
\end{abstract}

Received April 12, 2007.

Accepted July 9, 2007.

${ }^{1}$ On leave from Universidad de Caldas, Manizales, Colombia.

${ }^{2}$ Corresponding author: Jose-Angel.GOMEZ-RUIZ@ec.europa.eu

${ }^{3}$ Current address: Institute for Reference Materials and Measurements (IRMM), Food Safety and Quality Unit, Retieseweg, 2440 Geel, Belgium. theless, the perceived aroma could not be related to the volatile compounds analyzed by purge and trap coupled to a GC-MS apparatus.

The aim of this work was to identify and quantify the volatile compounds responsible for the characteristic floral or rose-like flavor observed in these fractions. For this purpose, volatile compounds contained in the different fractions were analyzed by simultaneous distillation extraction (SDE) in 2 configurations (using pentane or dichloromethane as extracting solvents) and purge-and-trap analysis. In addition, fractions were subjected to organoleptic analysis, comparing them to pure standards.

The WSF from 3 different Protected Denomination of Origin Manchego cheeses ripened for 4 mo were extracted and fractionated by gel permeation chromatography on Sephadex G-10 (1.6 ×60 cm, Pharmacia, Uppsala, Sweden) according to Taborda et al. (2003). Five fractions were obtained from each cheese, and 2 of them (F4 and F5) were studied in this work.

Simultaneous distillation extraction was carried out using camphor as internal standard following the method described by Gómez-Ruiz et al. (2001). Two configurations of the equipment were used: one using pentane as the solvent and the other using dichloromethane. The SDE extracts were analyzed by gas chromatography with flame-ionization detection (Carlo Erba HRGC Mega2 Series, Carlo Erba, Rodano, Italy) equipped with a Carbowax-20M capillary column (50 $\mathrm{m} \times 0.25 \mathrm{~mm} \times 0.25 \mu \mathrm{m})$. Chromatographic conditions were as follows: initial temperature of $60^{\circ} \mathrm{C}$, increased at $20^{\circ} \mathrm{C} / \mathrm{min}$ up to $180^{\circ} \mathrm{C}$, and maintained for $50 \mathrm{~min}$. Injections were made in split mode (1:50) with nitrogen as the carrier gas. Purge-and-trap analysis was carried out as described by Valero et al. (2000) using a concentrator (Hewlett-Packard 7695, Palo Alto, CA) with a Tenax trap (Tekmar, Cincinnati, OH), coupled to a Hewlett-Packard 5890 Series II gas chromatograph and a 5971A mass spectrometric detector working in electron ionization mode at $70 \mathrm{eV}$. Helium was used as carrier gas throughout the system. Ethyl pentanoate 
Table 1. Flavor descriptors and scores in Protected Denomination of Origin Manchego cheese fractions F4 and F5

\begin{tabular}{lcc}
\hline & \multicolumn{2}{c}{ Score } \\
\cline { 2 - 3 } Descriptor & F4 & F5 \\
\hline Fresh milk & - & 0.20 \\
Boiled milk & - & 0.80 \\
Cheesy & 0.40 & 0.60 \\
Floral & 1.20 & - \\
\hline
\end{tabular}

was used as internal standard. Five calibration standard solutions were prepared with increasing concentrations of phenylacetaldehyde, 2-phenylethyl acetate, 1-phenyl-2-hexanol, 2-phenylpropanol, and 2-phenylethanol in water (from 0.01 to $10 \mu \mathrm{g} / \mathrm{g}$ ).

Sensorial analysis was conducted by a panel of 5 trained members. Samples $(\sim 2 \mathrm{~mL})$ of cheese fractions and standard solutions were tasted. Panelists were requested to rank the intensity of flavor and to describe it. Intensity scale scores were 1 = low, $4=$ medium, and 7 = high. Different descriptive terms (vegetable, animal, lactic, fruity, spiced, floral, etc.) were proposed according to the aroma wheel of Bérodier et al. (1997).

Water solutions of phenylacetaldehyde (from 0.1 to $10 \mathrm{mg} / \mathrm{kg}$ ) and 2-phenylethanol (from 0.1 to $44 \mathrm{mg} / \mathrm{kg}$ ) were used to calibrate the perception of floral aroma in fractions F4 and F5.

Table 1 shows the sensory analysis of fractions F4 and F5 obtained from Manchego cheese. Only fraction F4 was described as having a floral, rose-like flavor by the panelists. However, the 2 fractions were subjected to purge-and-trap analysis and SDE. Analysis by purge and trap failed to find volatile compounds possessing floral odor, despite the detection of several compounds such as methyl ketones (from 3 to 7 carbon atoms), methyl and ethyl esters (from 3 to 8 carbon atoms), aldehydes (mainly 2-methylbutanal and 3-methylbutanal), and branched alcohols (3-methylbutanol, 3-methylpropanol). The SDE experiments carried out with pentane as the extracting solvent allowed us to detect an important amount of secondary alcohols (2-heptanol being the most abundant), odd-chain methyl ketones (from 5 to 13 carbon atoms), and ethyl esters (evenchain from ethylbutyrate to ethyl decanoate) in both fractions. These compounds have been previously described in other Manchego cheeses studied by using the same technique (Gómez-Ruiz et al., 2001). Although ethyl esters and some methyl ketones are known for their strong fruity character, secondary alcohols are typical components of blue cheese flavor. However, no compounds providing a floral note were detected.

The use of dichloromethane as the extracting solvent in the SDE technique made it possible to detect phenylacetaldehyde and 2-phenylethanol as 2 of the main com-
Table 2. Quantification of compounds ( $\mu \mathrm{g} / \mathrm{kg}$ ) with floral $/$ rose aroma in F4 and F5 fractions of Protected Denomination of Origin Manchego cheeses

\begin{tabular}{llcc}
\hline Compound & \multicolumn{1}{c}{ F4 } & F5 & $\begin{array}{c}\text { Reported } \\
\text { threshold } \\
(\mu \mathrm{g} / \mathrm{kg})^{2}\end{array}$ \\
\hline $\begin{array}{l}\text { Phenylacetaldehyde } \\
\text { 2-phenylethanol }\end{array}$ & $125 \pm 12.2$ & $45 \pm 4.2$ & 40 \\
\hline
\end{tabular}

${ }^{1}$ Values are expressed as the mean \pm SD calculated from the analysis by duplicate of 3 cheeses.

${ }^{2}$ Thresholds reported by Dunn and Lindsay (1985).

pounds in fraction F4. In fraction F5, small quantities of these 2 compounds were also detected. The amount of these compounds found in cheese fractions F4 and F5 is shown in Table 2. For quantification, calibration curves were adjusted to $\mathrm{y}=3,785 \mathrm{x}-7,535\left(\mathrm{R}^{2}=0.988\right)$ for phenylacetaldehyde, and $\mathrm{y}=1,691 \mathrm{x}-9,385\left(\mathrm{R}^{2}=\right.$ 0,958 ) for 2-phenylethanol. Relative response factors of 0.79 and 0.87 were calculated for phenylacetaldehyde and 2-phenylethanol, respectively. Phenylacetaldehyde and 2-phenylethanol have been described as possessing a floral/rose-like aroma (Dunn and Lindsay, 1985) and have been identified in other cheeses (Kubickova and Grosch, 1997; Rychlik and Bosset, 2001). Lactic acid bacteria can synthesize phenylacetaldehyde and 2-phenylethanol from the catabolism of aromatic amino acids, especially from phenylalanine. The enzyme-mediated transamination, decarboxylation, and reduction reactions of aromatic amino acids are the source of these 2 compounds.

Thresholds of phenylacetaldehyde and 2-phenylethanol have been described in the literature as 40 and 240 $\mu \mathrm{g} / \mathrm{kg}$, respectively (Dunn and Lindsay, 1985). Therefore, it can be seen (Table 2) that phenylacetaldehyde and 2-phenylethanol were present in fraction F4 at greater concentrations than their respective thresholds. For fraction F5, phenylacetaldehyde was slightly above its threshold and 2-phenylethanol was detected substantially below. This could explain why the floral/ rose aroma was detected in fraction F4 but not fraction F5 (Table 1).

We have demonstrated that the WSF obtained from Manchego cheese and described by panelists as possessing floral/rose notes (fraction F4) showed important amounts of phenylacetaldehyde and 2-phenylethanol. These compounds are typically described as having flo$\mathrm{ral} /$ rose aromas and, therefore, their contribution to the peculiar flavor found in fraction F4 seems evident. Although these compounds have been reported to be responsible for unclean flavor in Cheddar cheese (Carunchia Whetstine et al., 2005), they have been patented along with other compounds to impart flavor to unripened cheese (Freytag et al., 1976). The contribution of 
phenylacetaldehyde and 2-phenylethanol to the overall odor of Manchego cheeses will be the subject of further study.

\section{ACKNOWLEDGMENTS}

This work was supported by project FAIR-CT97-3173 and 1FD-97-0166. G. T. wishes to express his appreciation to Colciencias for his fellowship and also to Universidad de Caldas (Manizales, Colombia).

\section{REFERENCES}

Bérodier, F., P. Lavanchy, M. Zannoni, J. Casals, L. Herrero, and C. Adamo. 1997. Guide d'évaluation olfacto-gustative des fromages à pâte dure et semi-dure. Lebensm. Wiss. Technol. 30:653-664.

Carunchia Whetstine, M. E., K. R. Cadwallader, and M. A. Drake. 2005. Characterization of aroma compounds responsible for the rosy/floral flavour in Cheddar cheese. J. Agric. Food Chem. 53:3126-3132.

Dunn, H., and R. Lindsay. 1985. Evaluation of the role of microbial Strecker-derived aroma compounds in unclean-type flavors of Cheddar cheese. J. Dairy Sci. 68:2859-2874.

Engels, W. J. M., R. Dekker, C. de Jong, R. Neeter, and S. Visser. 1997. A comparative study of volatile compounds in the water- soluble fraction of various types of ripened cheese. Int. Dairy J. 7:255-263.

Freytag, W. G., K. H. Ney, and I. P. G. Wirotama. 1976. US Patent 3978242. Cheese flavor. Lever Brothers Co., New York, NY, assignee.

Gómez-Ruiz, J. A., C. Ballesteros, M. A. Gonzalez-Viñas, L. Cabezas, and I. Martínez-Castro. 2001. Relationship between volatile compounds and odour in Manchego cheese: Comparison between artisanal and industrial cheeses at different ripening times. Lait 82:613-628.

Kubickova, J., and W. Grosch. 1997. Evaluation of potent odorants of Camembert cheese by dilution and concentration techniques. Int. Dairy J. 7:65-70.

Rychlik, M., and J. O. Bosset. 2001. Flavour and off-flavour compounds of Swiss Gruyere cheese. Evaluation of potent odorants. Int. Dairy J. 11:895-901.

Salles, C., C. Septier, F. Roudot-Algaron, A. Guillot, and P. X. Etievant. 1995. Sensory and chemical analysis of fractions obtained by gel permeation of water-soluble Comte cheese extracts. J. Agric. Food Chem. 43:1659-1668.

Taborda, G., E. Molina, I. Martínez-Castro, M. Ramos, and L. Amigo. 2003. Composition of the water-soluble fraction of different Spanish cheeses. J. Agric. Food Chem. 51:270-276.

Valero, E., M. J. Villaseñor, J. Sanz, and I. Martínez-Castro. 2000. Comparison of two methods based on dynamic head-space for GCMS analysis of volatile components of cheeses. Chromatographia 38:286-294. 